Article

\title{
Long-Term Impact of COVID-19 on Mental Health among the General Public: A Nationwide Longitudinal Study in China
}

\author{
Le Shi ${ }^{1,+}+\mathbb{D}$, Zheng-An Lu ${ }^{1,+}{ }^{,}$Jian-Yu Que ${ }^{1}$, Xiao-Lin Huang ${ }^{2}$, Qing-Dong Lu ${ }^{3,4}$, Lin Liu ${ }^{3,4}$, Yong-Bo Zheng ${ }^{5}$, \\ Wei-Jian Liu ${ }^{1}$, Mao-Sheng Ran ${ }^{6}$, Kai Yuan ${ }^{1}$, Wei Yan ${ }^{1}$, Yan-Kun Sun ${ }^{1}$, Si-Wei Sun ${ }^{1}$, Jie Shi ${ }^{3}$, Thomas Kosten ${ }^{7}$, \\ Yan-Ping Bao ${ }^{3,4, *}$ and Lin $\mathrm{Lu}^{1,3,5,8, *}$
}

check for

updates

Citation: Shi, L.; Lu, Z.-A.; Que, J.-Y. Huang, X.-L.; Lu, Q.-D.; Liu, L.;

Zheng, Y.-B.; Liu, W.-J.; Ran, M.-S.; Yuan, K.; et al. Long-Term Impact of COVID-19 on Mental Health among the General Public: A Nationwide Longitudinal Study in China. Int. J. Environ. Res. Public Health 2021, 18, 8790. https://doi.org/10.3390/ ijerph18168790

Academic Editor: Paul B. Tchounwou

Received: 8 July 2021

Accepted: 11 August 2021

Published: 20 August 202

Publisher's Note: MDPI stays neutral with regard to jurisdictional claims in published maps and institutional affiliations.

Copyright: (C) 2021 by the authors Licensee MDPI, Basel, Switzerland. This article is an open access article distributed under the terms and conditions of the Creative Commons Attribution (CC BY) license (https:// creativecommons.org/licenses/by/ $4.0 /)$.
1 Peking University Sixth Hospital, Peking University Institute of Mental Health, NHC Key Laboratory of Mental Health (Peking University), National Clinical Research Center for Mental Disorders (Peking University Sixth Hospital), Peking University, Beijing 100191, China; leshi@bjmu.edu.cn (L.S.); 1911210616@bjmu.edu.cn (Z.-A.L.); quejianyu@bjmu.edu.cn (J.-Y.Q.); weijian191954@stu.pku.edu.cn (W.-J.L.); yuankai@pku.edu.cn (K.Y.); weiyan@bjmu.edu.cn (W.Y.); yankunsun@bjmu.edu.cn (Y.-K.S.); siwei341105@bjmu.edu.cn (S.-W.S.)

2 Savaid Medical School, University of Chinese Academy of Sciences, Beijing 100049, China; huangxiaolin18@mails.ucas.ac.cn

3 Beijing Key Laboratory of Drug Dependence, National Institute on Drug Dependence, Peking University, Beijing 100191, China; 1410306211@pku.edu.cn (Q.-D.L.); liuln@pku.edu.cn (L.L.); shijie@bjmu.edu.cn (J.S.)

4 School of Public Health, Peking University, Beijing 100191, China

5 Peking-Tsinghua Center for Life Sciences, PKU-IDG/McGovern Institute for Brain Research, Beijing 100871, China; yongbozheng@bjmu.edu.cn

6 Department of Social Work and Social Administration, University of Hong Kong, Hong Kong, China; msran@hku.hk

7 Department of Psychiatry, Baylor College of Medicine, Houston, TX 77030, USA; kosten@bcm.edu

8 Research Unit of Diagnosis and Treatment of Mood Cognitive Disorder (2018RU006), Chinese Academy of Medical Sciences, Beijing 100191, China

* Correspondence: baoyp@bjmu.edu.cn (Y.-P.B.); linlu@bjmu.edu.cn (L.L.); Tel.: +86-10-8280-2470-412 (Y.-P.B.); +86-10-8280-5308 (L.L.);

Fax: +86-10-6203-2624 (Y.-P.B.); +86-10-6202-6310 (L.L.)

+ These authors contributed equally to this work.

Abstract: COVID-19 might have long-term mental health impacts. We aim to investigate the longitudinal changes in mental problems from initial COVID-19 peak to its aftermath among general public in China. Depression, anxiety and insomnia were assessed among a large-sample nationwide cohort of 10,492 adults during the initial COVID-19 peak (28 February 2020 to 11 March 2020) and its aftermath (8 July 2020 to 8 August 2020) using the Patient Health Questionnaire-9, Generalized Anxiety Disorder-7, and Insomnia Severity Index. We used generalized estimating equations and linear mixed models to explore factors associated with long-term mental health symptoms during COVID-19. During the five months, mental health symptoms remained consistently elevated (baseline $46.4 \%$; follow-up $45.1 \%$ ). Long-term depression, anxiety and insomnia were associated with several personal and work-related factors including quarantine (adjusted OR for any mental health symptoms 1.31, 95\%CI 1.22-1.41, $p<0.001)$, increases in work burden after resuming work $(1.77$, $1.65-1.90, p<0.001)$, occupational exposure risk to COVID-19 $(1.26,1.14-1.40, p<0.001)$ and living in places severely affected by initial COVID-19 peak $(1.21,1.04-1.41, p=0.01)$ or by a COVID-19 resurgence $(1.38,1.26-1.50, p<0.001)$. Compliance with self-protection measures, such as wearing face masks $(0.74,0.61-0.90, p=0.003)$, was associated with lower long-term risk of mental problems. The findings reveal a pronounced and prolonged mental health burden from the initial COVID-19 peak through to its aftermath in China. We should regularly monitor the mental health status of vulnerable populations throughout COVID-19.

Keywords: COVID-19; mental health; longitudinal; China 


\section{Introduction}

Despite the incidence of over 100 million COVID-19 infections and three million deaths from around the world, the pandemic is far from being controlled [1]. Because of the high transmission rate and severe pathology from the newly emerged coronavirus, infected cases and deaths continue to soar despite widespread public health measures, including lockdowns, quarantine, social distancing and business closures [2]. The pandemic is expected to last for an extended period of time, as long-term effectiveness of vaccines and other control methods are yet to be determined [3]. Thus, the dynamic impact of COVID-19 should be deeply researched.

COVID-19 and its corresponding economic and social burden have a negative immediate impact on mental health [4-6]. The prevalence of depression, anxiety and insomnia during the initial COVID-19 outbreak was approximately 30\% both in China and abroad, which was substantially higher compared with $6.0 \%$ for depression, $5.3 \%$ for anxiety and $15.0 \%$ for insomnia before the COVID-19 outbreak [4,7-13]. Psychological risk is disproportionately distributed across demographic subgroups during initial COVID-19 peak. For instance, men show higher risk for mental health problems than women, and public health measures, including quarantine, lockdowns and social distancing appear to increase risk for mental health problems [9,14-17]. Moreover, previous studies after SARS indicated prolonged distress after exposure to the pandemic, and its long-term influencing factors include demographics (i.e., gender and age), personal factors associated with SARS (i.e., SARS infection, quarantine and social distancing), and work-related factors (i.e., direct engagement in SARS control and occupational exposure to SARS) [18-21]. Existing longitudinal studies have identified a persistent mental health burden under the substantial and enduring strain of COVID-19 in many countries, including the United States, the United Kingdom, and Italy, but little evidence exists in China [22-25]. In China, the main wave of COVID-19 was largely put under control and lockdown was lifted in April, 2020. However, sporadic cases and local resurgences have occurred continuously across the country, and nationwide epidemic prevention and control have been continuously enforced to suppress another large-scale outbreak. Thus, continuous emergence of sporadic cases, persistence of public health measures, sustained economic stress and an uncertain efficacy of potential treatment agents still pose considerable threats to mental health [26-28].

Longitudinally tracking mental health changes is essential for mental health management [29], but most studies on the psychological impact from COVID-19 are cross-sectional or conducted within the initial peak or lockdown period and thereby fail to capture changing trends across different pandemic stages of COVID-19. Additionally, though many factors are associated with immediate mental health symptoms, these factors can induce sustained mental health changes, and new risks or protective factors may emerge after the initial peak, when the lockdown is lifted, and economic and social activity restart. Given the continuous emergence of sporadic cases, sustained pandemic control measures and remarkable social disruptions due to COVID-19, we hypothesize that severe mental health symptoms persist from initial COVID-19 peak to its aftermath, and factors for long-term distress may differ from those for immediate stress responses to COVID-19. Therefore, the objective of this research is to explore longitudinal changes in mental health symptoms and their associated factors from initial COVID-19 to its aftermath, by repeatedly measuring mental health symptoms among a national cohort in China.

\section{Methods}

\subsection{Study Design}

We conducted a longitudinal cohort study, in which participants were recruited from the health page of Chinese website Joybuy. Joybuy is a large ecommerce and information service platform that provides online health products and services in China with 0.44 billion active users from all 34 province-level regions in China, the members of which are generally young and highly educated, who acquire membership by online registration with an annual fee $[9,17]$. During the baseline survey fielded from 28 February 2020 to 11 March 2020, 
which was the initial peak of COVID-19, all registered members were allowed to click on a link on health page of website Joybuy to complete the survey until the convenience sample covered all 34 province-level regions in China. The follow-up survey was fielded from 8 July 2020 to 8 August 2020, when the main COVID-19 wave had been basically controlled, and lockdown had been lifted for about three months in China. At the follow-up survey, we adopted two methods to recruit participants. Firstly, questionnaire links were sent via the message platform of Joybuy to all baseline participants, who were identified by their unique ID numbers. At the same time, to recruit new participants, we put our second-wave survey link on the health page of Joybuy, allowing new participants to voluntarily click on it to participate the second-wave survey. At both the baseline and follow-up survey, links were attached with online shopping vouchers. To allow for comparison between baseline and follow-up, participants who responded to both surveys were included in the final analysis in this study. The study was approved by the ethics committee of Peking University Sixth Hospital (Institute of Mental Health) (ethical code: 2020-2-21-2). Informed consent was received online before the respondents began the surveys. This study follows the American Association for Public Opinion Research (AAPOR) reporting guideline.

\subsection{Participants}

The participants in the two surveys were all registered members of Joybuy. At baseline, 56,679 adults providing valid age information were included, as detailed elsewhere [9]. At the follow-up, of the 56,679 baseline participants to whom we sent follow-up survey links, 17,576 clicked on the links and 10,867 commenced the survey. Finally, 10,492 participants from 32 provinces in China provided informed consent and completed the follow-up survey (effective follow-up rate: $18.5 \%$ ). Data from the two surveys were matched individually according to unique ID numbers from the Joybuy website. Detailed information about recruitment and selection of participants in the follow-up survey are presented in Figure 1.

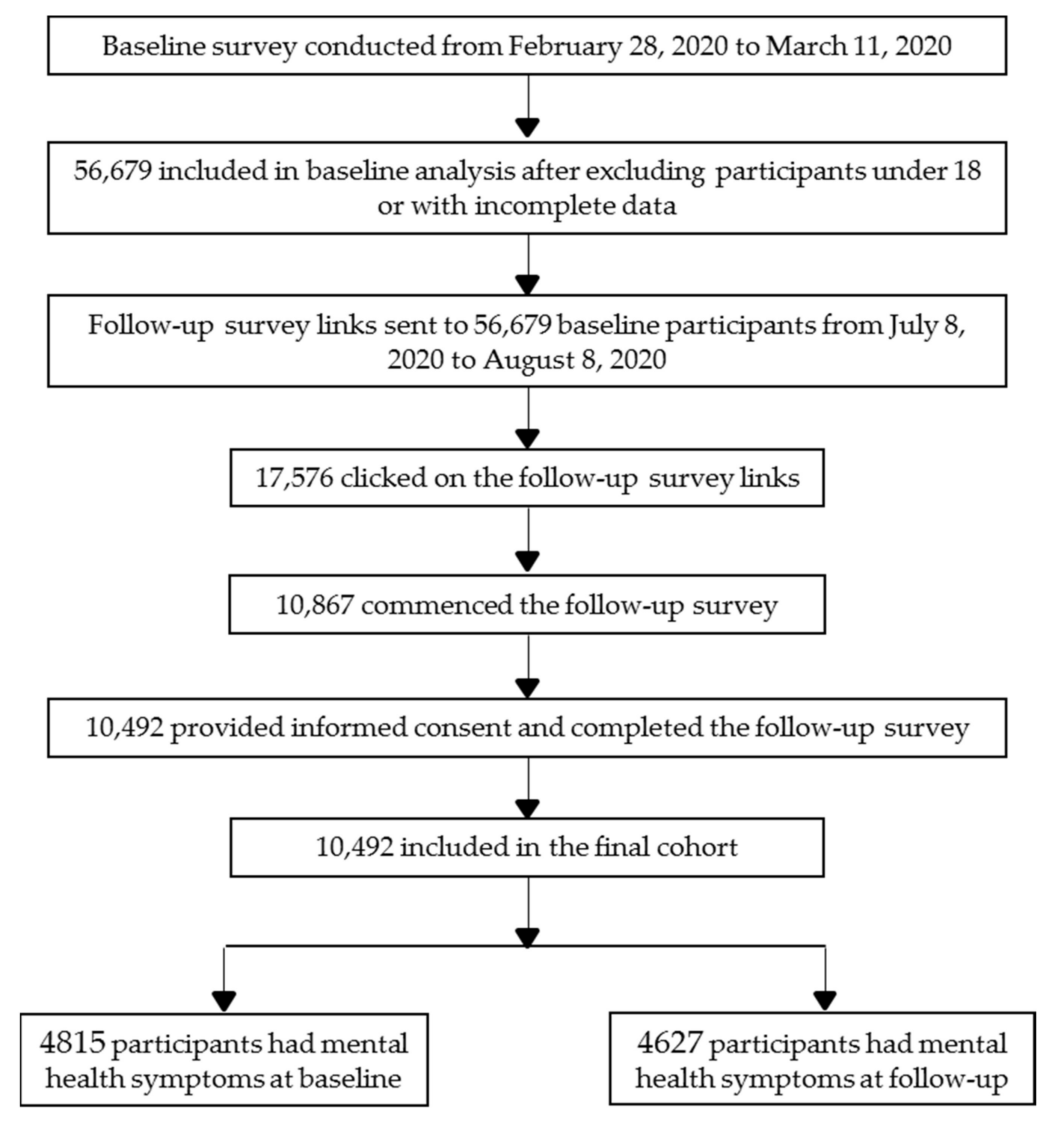

Figure 1. Flow chart of participants selection. 


\subsection{Measures and Variables}

Each survey lasted $\sim 20 \mathrm{~min}$ and had four parts. The first part gathered demographic information of the participants. The second part asked epidemic-related questions. The third part evaluated quarantine conditions and social attitudes toward the COVID-19 pandemic. We provided detailed information about these three parts previously [9]. The fourth part consisted of three standardized scales, including the Chinese versions of Patient Health Questionnaire-9 (PHQ-9), Generalized Anxiety Disorder-7 (GAD-7), and Insomnia Severity Index (ISI), that measured symptoms of depression, anxiety, and insomnia, respectively. PHQ-9 is a 9-item questionnaire based on the diagnosis of a major depressive episode according to the DSM systems with a Cronbach's $\alpha$ of 0.89 , sensitivity of 0.88 and specificity of 0.88 to detect depression [30]. GAD-7 is a 7-item questionnaire considered as a reliable tool to detect anxiety disorder with a Cronbach's $\alpha$ of 0.89 , sensitivity of 0.89 and specificity of 0.82 [31]. ISI is a 7 item questionnaire with a Cronbach's $\alpha$ of 0.92 , and is found to produce a sensitivity of 0.82 and a specificity of 0.82 in detecting clinical insomnia [32]. We calculated participants' scores and used cutoff scores of 5, 5, and 8 to categorize them as depressed, anxious and having insomnia symptoms. We added extra questions specific to the follow-up survey to inquire about new situations after the initial peak of COVID-19, including COVID-19 resurgences, whether wearing face masks voluntarily when going out, whether reducing gatherings voluntarily, whether seeking psychological consultation, and self-perceived increases in work burden after resuming work. The summary of the questionnaire questions for both surveys is provided in Table S2.

We considered three groups of potential factors associated with long-term mental health symptoms: (1) Demographics: gender, age, living area, educational level, marital status, monthly family income, history of chronic diseases, history of psychiatric disorders, and family history of psychiatric disorders. (2) Personal factors associated with COVID-19: personal infection, family members infection, living in the province most severely affected by initial peak, experiencing quarantine, living in places with a COVID-19 resurgence, wearing face masks voluntarily when going out, reducing gatherings voluntarily and seeking psychological consultation. (3) Work-related factors: direct engagement in workrelated COVID-19 control, self-perceived occupational exposure risk to COVID-19, and self-perceived increase in work burden after resuming work. Table S3 presents detailed descriptions for variable constructing approaches based on participants' responses to questionnaire questions on these factors.

\subsection{Statistical Analyses}

Descriptive statistics were used to present the baseline demographic characteristics of the total baseline sample, participants who responded to the follow-up survey and those who did not respond. Weight based on gender (male or female), age (18-39 years or $\geq 40$ years), living area (urban or rural), educational level (lower than college school or college school or higher), marital status (married or unmarried), geographical regions and history of chronic diseases (yes or unknown/no) in the baseline sample was applied to adjust for proportion differences between the baseline total sample and the longitudinal cohort. Prevalence of symptoms of depression, anxiety, insomnia, and any mental health problems at both surveys was calculated using the aforementioned cutoff scores, and reported as the percentages of cases. $95 \%$ confidence intervals (CIs) were produced by the exact binomial methods. Average scores of PHQ-9, GAD-7 and ISI at both surveys were presented as medians and interquartile ranges (IQRs). McNemar $\chi^{2}$ tests and paired-samples Wilcoxon tests were respectively adopted to test the statistically significant differences in prevalence and scores of mental health symptoms between baseline and follow-up survey. Proportions of new onset and persistent mental health symptoms were calculated among participants who were screened as symptom negative or positive at baseline, respectively.

To explore the associated factors of long-term mental health symptoms, we performed two analyses. Generalized estimating equation models with a binomial distribution were employed, in which the outcome variables were the categorical mental health status 
(yes/no), with survey order as repeated effect and within-subject effect, and participant ID number as covariate factor. All potential factors were first entered into a univariable model to test for significance, and then a multivariable model was constructed by including all potential factors that showed significance in their individual models, as well as the variable of survey order. We chose the autoregressive correlation structure based on lower values for the Quasi Information Criterion. In addition, we fitted generalized linear mixed models with random within-subject intercepts and autoregressive covariance structures, in which the outcome variables were PHQ-9, GAD-7 and ISI scores. Fixed effects for all potential factors considered were first tested for significance in their individual models. We also tested the fixed effects for all factors with time interactions to explore factors associated with longitudinal mental health changes from baseline to follow-up. The multivariable model was constructed by including fixed effects for all potential factors and factor by time interactions that showed significance in individual models, with time coded as 0 at baseline and 5 at follow-up. We also tested models with both the random slopes and intercepts, and other covariance structures, and selected the final optimal model based on lower Akaike information criterion and likelihood ratio tests.

The level of significance was set to two sided $p<0.05$. All of the statistical analyses were performed using SPSS 22 software (SPSS, Chicago, IL, USA) and R version 4.0.3.

\section{Results}

\subsection{Demographic and Epidemic-Related Characteristics of Participants}

Among the 10,492 participants included in the longitudinal cohort, the mean (SD) age was $36.87(8.21)$, and 4465 (42.6\%) were male, 9769 (93.1\%) lived in urban areas, 8391 $(80.0 \%)$ had a college school or higher educational level, 8467 (80.7\%) were married, and $2444(23.3 \%)$ had family monthly income lower than 5000 yuan. Compared to those who did not participate in the follow-up survey, those who took part in the follow-up survey were more likely to be female, older, poorly educated, married and report history of chronic diseases. Detailed baseline characteristics of the longitudinal cohort, the total baseline sample and weighted longitudinal cohort sample are shown in Table 1.

Table 1. Baseline demographic characteristics of participants.

\begin{tabular}{|c|c|c|c|c|c|}
\hline Factors & $\begin{array}{c}\text { Total Number of } \\
\text { Participants at } \\
\text { Baseline (\%) }\end{array}$ & $\begin{array}{c}\text { Number of Baseline } \\
\text { Participants Who } \\
\text { Responded to } \\
\text { Follow-Up Survey }(\%)\end{array}$ & $\begin{array}{l}\text { Number of Baseline } \\
\text { Participants Who Did } \\
\text { Not Respond to } \\
\text { Follow-Up Survey }(\%)\end{array}$ & $p$-Value ${ }^{\mathrm{a}}$ & $\begin{array}{l}\text { Weighted Number } \\
\text { of Participants }(\%)\end{array}$ \\
\hline \multirow{2}{*}{$\begin{array}{c}\text { Overall } \\
\text { Mean (SD) for age, } \\
\text { years }\end{array}$} & $56,679(100.0)$ & $10,492(100.0)$ & $46,187(100.0)$ & - & $10,492(100.0)$ \\
\hline & $35.97(8.22)$ & $36.87(8.21)$ & $35.76(8.21)$ & $<0.001^{c}$ & - \\
\hline \multicolumn{6}{|l|}{ Age, years } \\
\hline $18-39$ & 39,468 (69.6) & $6815(65.0)$ & $32,653(70.7)$ & $<0.001$ & 7306 (69.6) \\
\hline$\geq 40$ & $17,211(30.4)$ & 3677 (35.0) & $13,534(29.3)$ & & $3186(30.4)$ \\
\hline \multicolumn{6}{|l|}{ Gender } \\
\hline Male & 27,149 (47.9) & 4465 (42.6) & $22,684(49.1)$ & $<0.001$ & $5026(47.9)$ \\
\hline Female & $29,530(52.1)$ & $6027(57.4)$ & $23,503(50.9)$ & & $5466(52.1)$ \\
\hline \multicolumn{6}{|l|}{ Living area } \\
\hline Urban & $52,839(93.2)$ & 9769 (93.1) & $43,070(93.3)$ & 0.60 & 9781 (93.2) \\
\hline Rural & $3840(6.8)$ & $723(6.9)$ & 3117 (6.7) & & $711(6.8)$ \\
\hline \multicolumn{6}{|l|}{ Education } \\
\hline $\begin{array}{l}\text { Lower than college } \\
\text { school }\end{array}$ & $9540(16.8)$ & $2101(20.0)$ & 7439 (16.1) & $<0.001$ & $1766(16.8)$ \\
\hline $\begin{array}{c}\text { College school or } \\
\text { higher }\end{array}$ & $47,139(83.2)$ & $8391(80.0)$ & $38,748(83.9)$ & & $8726(83.2)$ \\
\hline \multicolumn{6}{|l|}{ Marital status } \\
\hline Married & $43,763(77.2)$ & 8467 (80.7) & $35,296(76.4)$ & $<0.001$ & 8101 (77.2) \\
\hline Unmarried & $12,916(22.8)$ & 2025 (19.3) & $10,891(23.6)$ & & $2391(22.8)$ \\
\hline
\end{tabular}


Table 1. Cont.

\begin{tabular}{|c|c|c|c|c|c|}
\hline Factors & $\begin{array}{c}\text { Total Number of } \\
\text { Participants at } \\
\text { Baseline (\%) }\end{array}$ & $\begin{array}{l}\text { Number of Baseline } \\
\text { Participants Who } \\
\text { Responded to } \\
\text { Follow-Up Survey }(\%)\end{array}$ & $\begin{array}{c}\text { Number of Baseline } \\
\text { Participants Who Did } \\
\text { Not Respond to } \\
\text { Follow-Up Survey (\%) }\end{array}$ & $p$-Value ${ }^{a}$ & $\begin{array}{l}\text { Weighted Number } \\
\text { of Participants (\%) }^{b}\end{array}$ \\
\hline \multicolumn{6}{|l|}{$\begin{array}{c}\text { Monthly income, } \\
\text { yuan }\end{array}$} \\
\hline 0-4999 & $13,016(23.0)$ & $2444(23.3)$ & $10,572(22.9)$ & 0.37 & 2402 (22.9) \\
\hline$\geq 5000$ & $43,663(77.0)$ & 8048 (76.7) & $35,615(77.1)$ & & $8090(77.1)$ \\
\hline \multicolumn{6}{|l|}{ Geographical region } \\
\hline Eastern China & $23,172(40.9)$ & $4283(40.8)$ & $18,889(40.9)$ & 0.01 & $4289(40.9)$ \\
\hline Northern China & $10,227(18.0)$ & 1849 (17.6) & $8378(18.1)$ & & $1893(18.0)$ \\
\hline Northeastern China & $3921(6.9)$ & $781(7.4)$ & $3140(6.8)$ & & $726(6.9)$ \\
\hline Northwestern China & $1348(2.4)$ & $219(2.1)$ & $1129(2.4)$ & & $250(2.4)$ \\
\hline Central China & $4803(8.5)$ & $873(8.3)$ & $3930(8.5)$ & & $889(8.5)$ \\
\hline Southern China & $10,028(17.7)$ & $1935(18.4)$ & 8093 (17.5) & & $1856(17.7)$ \\
\hline South west China & $3156(5.6)$ & $547(5.2)$ & $2609(5.6)$ & & $584(5.6)$ \\
\hline Missing values & $24(0.0)$ & $5(0.0)$ & $19(0.0)$ & & $4(0.0)$ \\
\hline \multicolumn{6}{|l|}{$\begin{array}{c}\text { History of chronic } \\
\text { diseases }\end{array}$} \\
\hline Yes & $3274(5.8)$ & $664(6.3)$ & $2610(5.7)$ & 0.007 & $606(5.8)$ \\
\hline Unknown/No & $53,405(94.2)$ & $9828(93.7)$ & $43,577(94.3)$ & & $9886(94.2)$ \\
\hline \multicolumn{6}{|l|}{$\begin{array}{l}\text { History of } \\
\text { psychiatric } \\
\text { disorders }\end{array}$} \\
\hline Yes & $161(0.3)$ & $31(0.3)$ & $130(0.3)$ & 0.81 & $32(0.3)$ \\
\hline Unknown/No & $56,518(99.7)$ & $10,461(99.7)$ & 46,057 (99.7) & & $10,460(99.7)$ \\
\hline \multicolumn{6}{|l|}{$\begin{array}{c}\text { Family history of } \\
\text { psychiatric } \\
\text { disorders }\end{array}$} \\
\hline Yes & $396(0.7)$ & $64(0.6)$ & $332(0.7)$ & 0.23 & $64(0.6)$ \\
\hline Unknown/No & $56,283(99.3)$ & $10,428(99.4)$ & 45,855 (99.3) & & $10,428(99.4)$ \\
\hline
\end{tabular}

${ }^{a} \chi^{2}$ tests were used to compare proportion of participants who responded to the follow-up survey across different strata of demographic factors. ${ }^{b}$ Weight was estimated based on gender (male or female), age (18-39 years or $\geq 40$ years), living area (urban or rural), educational level (lower than college school or college school or higher), marital status (married or unmarried), geographical regions and history of chronic diseases (yes or unknown/no) using the baseline sample. ${ }^{c} p$-Value from $t$ test.

\subsection{Change in Mental Health Symptoms from Baseline to Follow-Up Survey}

The weighted prevalence of any mental health symptoms was continuously elevated from the baseline survey at $46.4 \%(95 \%$ CI $45.4-47.3 \%)$ to the follow-up survey at $45.1 \%$ $(44.2-46.1 \%)$, although a slight but statistically significant decline was detected $(p=0.01)$. Depression significantly increased from $30.0 \%(29.2-30.9 \%)$ to $33.6 \%(32.7-34.5 \%, p<0.001)$, and insomnia significantly increased from $29.8 \%(28.9-30.7 \%)$ to $35.3 \%(34.4-36.2 \%, p<0.001)$. In contrast, anxiety symptoms decreased from $35.2 \%$ (34.3-36.1\%) to $32.5 \%$ (31.7-33.5\%, $p<0.001)$. Medians (IQR) of PHQ-9 scores increased from $0.0(0.0-6.0)$ to $0.0(0.0-8.0$, $p<0.001)$, and ISI scores increased from $4.0(1.0-8.0)$ to $4.0(1.0-9.0, p<0.001)$. In contrast, GAD-7 scores decreased from $1.0(0.0-7.0)$ to $0.0(0.0-7.0, p<0.001)$. Table 2 shows the changes in prevalence and scores of mental health symptoms in the cohort, and changes in scores of depression, anxiety and insomnia from baseline to follow-up are shown in Figures S1-S6.

We present mental health prevalence changes stratified by demographic, personal and work-related factors in Figure 2 and Table S4. Mental health symptoms declined from baseline to follow-up among females, mid-aged or elder people, urban residents, those poorly educated, participants with moderate or high incomes and married participants, while we identified no statistically significant difference in prevalence of any mental health symptoms from baseline to follow-up among males, young adults, rural residents, the highly educated, and impoverished participants. 
Table 2. Prevalence and scores of depression, anxiety, insomnia and any mental health symptoms at baseline and follow-up survey.

\begin{tabular}{|c|c|c|c|c|c|c|c|c|}
\hline \multirow{3}{*}{$\begin{array}{l}\text { Mental Health } \\
\text { Symptoms }\end{array}$} & \multicolumn{5}{|c|}{ Number of Participants with Mental Health Symptoms (\%, $95 \% \mathrm{CI})$} & \multicolumn{3}{|c|}{ Median Scores (IQR) } \\
\hline & \multicolumn{2}{|c|}{ Baseline $(\mathrm{N}=10,492)$} & \multicolumn{2}{|c|}{ Follow-Up $(\mathrm{N}=10,492)$} & \multirow{2}{*}{$p$-Value ${ }^{b}$} & \multirow{2}{*}{ Baseline } & \multirow{2}{*}{ Follow-Up } & \multirow{2}{*}{$p$-Value } \\
\hline & Unweighted & Weighted $^{\text {a }}$ & Unweighted & Weighted $^{\mathrm{a}}$ & & & & \\
\hline Anxiety & $3654(34.8,33.9-35.7)$ & $3693(35.2,34.3-36.1)$ & $3320(31.6,30.8-32.5)$ & $3415(32.5,31.7-33.5)$ & $<0.001$ & $1.0(0.0-7.0)$ & $0.0(0.0-7.0)$ & $<0.001$ \\
\hline Insomnia & $3066(29.2,28.4-30.1)$ & $3127(29.8,28.9-30.7)$ & $3610(34.4,33.5-35.3)$ & $3701(35.3,34.4-36.2)$ & $<0.001$ & $4.0(1.0-8.0)$ & $4.0(1.0-9.0)$ & $<0.001$ \\
\hline $\begin{array}{l}\text { Any mental health } \\
\text { symptoms }\end{array}$ & $4815(45.9,44.9-46.9)$ & $4865(46.4,45.4-47.3)$ & $4627(44.1,43.1-45.1)$ & $4733(45.1,44.2-46.1)$ & 0.01 & - & - & - \\
\hline
\end{tabular}




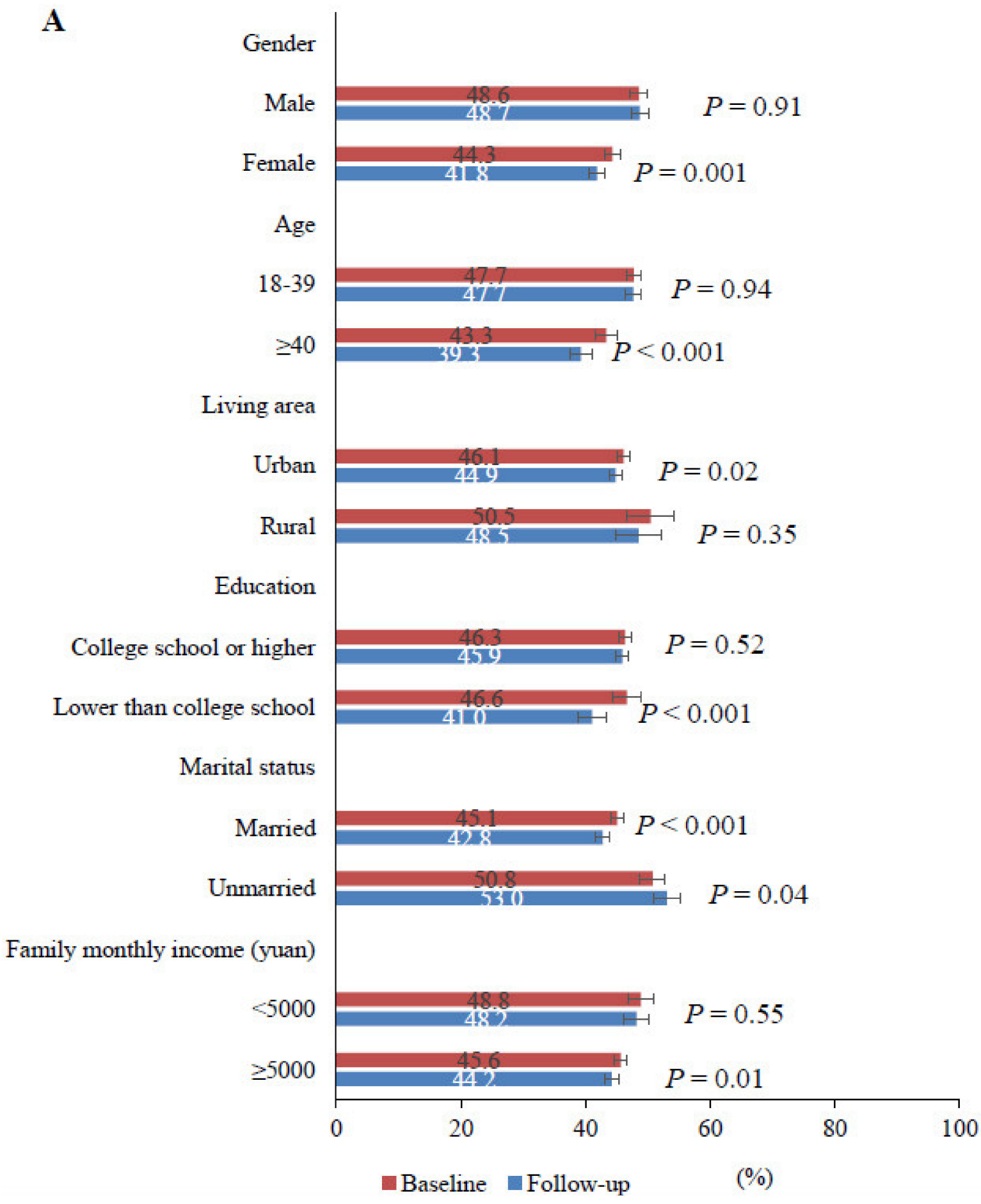

Figure 2. Cont. 


\section{B}

Family members of COVID-19 patients

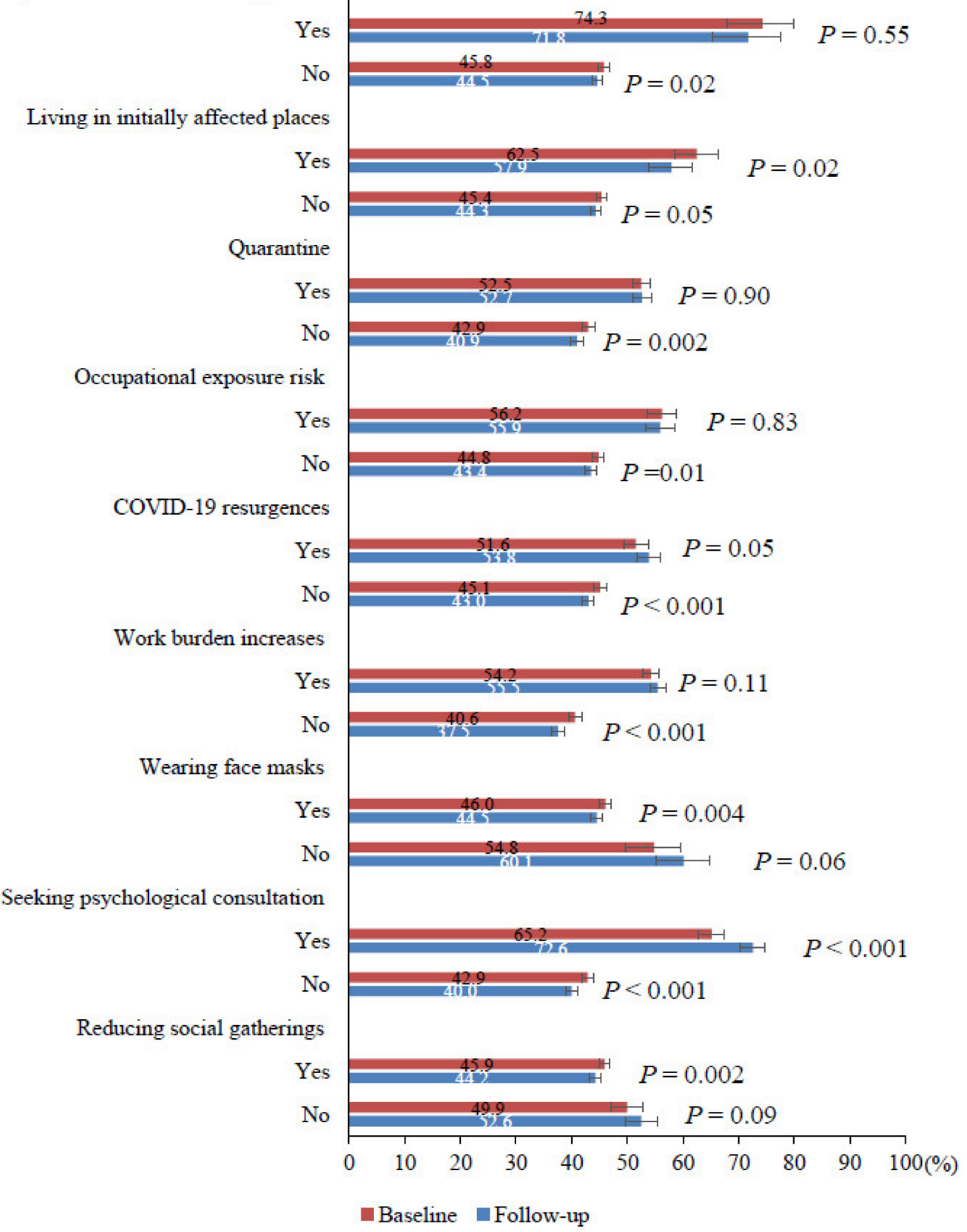

Figure 2. Changes in weighted prevalence of any mental health symptoms from baseline to follow-up survey. (A). Prevalence stratified by demographic-related factors. (B). Prevalence stratified by personal- and work-related epidemic factors. Any mental health symptoms is defined as having either depression, anxiety or insomnia. $p$-Values are from McNemar tests for statistically significant differences in prevalence of any mental health symptom in baseline vs. follow-up survey. The error bars indicate $95 \%$ CIs. 
Mental health symptoms also declined between baseline and follow-up in participants who were not family members of COVID-19 participants, lived in places most severely affected by initial peak, did not have quarantine experiences, occupational exposure risk, COVID-19 resurgence experiences or increases in work burden, and in participants who wore face masks, reduced social gatherings voluntarily or did not seek psychological consultation during follow-up. However, sustained mental health symptoms were observed among family members of COVID-19 patients, participants with quarantine experiences, with occupational exposure risk to COVID-19, with increases in work burden after resuming work, and those living in places with COVID-19 resurgences, and those who did not wear face masks when going out or did not reduce social gatherings. Within these subgroups, the prevalence of any mental health symptom at both surveys remained over $40 \%$, with no statistically significant difference observed between baseline and follow-up survey (all $p>0.05$ ).

\subsection{Proportions of New Onset and Persistent Mental Health Symptoms from Baseline to Follow-Up Survey}

At baseline 5627 participants reported no mental health symptom, and at follow-up $1374(24.4 \%)$ displayed new onset symptoms. At baseline 4865 participants reported any mental health symptoms, and at follow-up 3359 (69.0\%) reported persistent symptoms. Specifically, of participants denying depression, anxiety or insomnia at baseline, $20.1 \%$, $18.5 \%$ and $21.2 \%$ displayed new onset depression, anxiety or insomnia symptoms at followup. Among the participants reporting depression, anxiety or insomnia at baseline, $65.1 \%$, $58.5 \%$ and $68.4 \%$ reported persistent depression, anxiety and insomnia symptoms. The proportions of participants with new onset and persistent mental health symptoms are shown in Table 3.

Table 3. Proportions of new onset and persistent depression, anxiety, insomnia and any mental health symptoms from baseline to follow-up survey in the cohort.

\begin{tabular}{ccccc}
\hline \multirow{2}{*}{$\begin{array}{c}\text { Mental Health } \\
\text { Symptoms }\end{array}$} & \multicolumn{2}{c}{$\begin{array}{c}\text { Proportion of New Onset Symptoms among } \\
\text { Baseline Negative Participants }\end{array}$} & \multicolumn{2}{c}{$\begin{array}{c}\text { Proportion of Persistent Symptoms among } \\
\text { Baseline Positive Participants }\end{array}$} \\
\cline { 2 - 5 } & Unweighted n/N (\%) & Weighted n/N (\%) ${ }^{\text {a }}$ & Unweighted n/N (\%) & Weighted n/N (\%) a \\
\hline Depression & $1445 / 7421(19.5)$ & $1475 / 7341(20.1)$ & $1976 / 3071(64.3)$ & $2052 / 3151(65.1)$ \\
\hline Anxiety & $1220 / 6838(17.8)$ & $1256 / 6799(18.5)$ & $2100 / 3654(57.5)$ & $2159 / 3693(58.5)$ \\
\hline Insomnia & $1528 / 7426(20.6)$ & $1562 / 7365(21.2)$ & $2082 / 3066(67.9)$ & $2139 / 3127(68.4)$ \\
\hline $\begin{array}{c}\text { Any mental health } \\
\text { symptoms }\end{array}$ & $1346 / 5677(23.7)$ & $1374 / 5627(24.4)$ & $3281 / 4815(68.1)$ & $3359 / 4865(69.0)$ \\
\hline
\end{tabular}

a Weight was estimated based on gender (male or female), age (18-39 years or $\geq 40$ years), living area (urban or rural), educational level (lower than college school or college school or higher), marital status (married or unmarried), geographical regions and history of chronic diseases (yes or unknown/no) using the baseline sample.

\subsection{Factors Associated with Long-Term Positive of Mental Health Symptoms during the Course of COVID-19}

In the multivariable generalized estimation equation analysis, some personal factors were associated with all four of the long-term mental health symptoms and are presented in Table 4 , including living in places most severely affected by the initial peak (adjusted OR for any mental health symptoms $1.21,95 \%$ CI 1.04-1.41, $p=0.01)$ or with COVID-19 resurgences $(1.38,1.26-1.50, p<0.001)$, and quarantine experience $(1.31,1.22-1.41, p<0.001)$. Moreover, some work-related factors also showed significance in the analysis, including occupational exposure risk to COVID-19 $(1.26,1.14-1.40, p<0.001)$, and increases in work burden after resuming work $(1.77,1.65-1.90, p<0.001)$. Family members of COVID-19 patients $(2.10,1.61-2.74, p<0.001)$ and people seeking psychological consultation since COVID-19 $(2.57,2.33-2.85, p<0.001)$ also emerged as susceptible populations. Wearing facemasks voluntarily $(0.74,0.61-0.90, p=0.003)$ appeared to protect from long-term mental health symptoms. Factors associated with long-term depression, anxiety, insomnia and any mental health symptoms are presented in Table 4. 


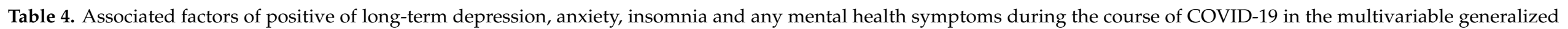
estimating equation models ${ }^{\mathrm{a}}$.

\begin{tabular}{|c|c|c|c|c|c|c|c|c|}
\hline \multirow{2}{*}{ Factors } & \multicolumn{2}{|c|}{ Depression } & \multicolumn{2}{|c|}{ Anxiety } & \multicolumn{2}{|c|}{ Insomnia } & \multicolumn{2}{|c|}{ Any Mental Health Symptoms } \\
\hline & OR $(95 \% C I)$ & $p$-Value & OR $(95 \% C I)$ & $p$-Value & OR $(95 \% C I)$ & $p$-Value & OR $(95 \% C I)$ & $p$-Value \\
\hline Gender: male (vs. female) & $1.19(1.11-1.28)$ & $<0.001$ & $1.04(0.97-1.12)$ & 0.30 & $1.18(1.10-1.27)$ & $<0.001$ & $1.08(1.01-1.16)$ & 0.03 \\
\hline Age(years) & $0.99(0.98-0.99)$ & $<0.001$ & $0.99(0.99-1.00)$ & $<0.001$ & $1.00(1.00-1.01)$ & 0.62 & $1.00(0.99-1.00)$ & 0.08 \\
\hline $\begin{array}{l}\text { Marital status: married (vs. } \\
\text { unmarried) }\end{array}$ & $0.85(0.77-0.94)$ & 0.001 & $0.95(0.86-1.04)$ & 0.25 & $0.78(0.71-0.86)$ & $<0.001$ & $0.83(0.75-0.91)$ & $<0.001$ \\
\hline $\begin{array}{l}\text { Family members of COVID-19 } \\
\text { patients: yes (vs. no) }\end{array}$ & $1.79(1.38-2.33)$ & $<0.001$ & $1.75(1.37-2.22)$ & $<0.001$ & $1.86(1.43-2.42)$ & $<0.001$ & $2.10(1.61-2.74)$ & $<0.001$ \\
\hline $\begin{array}{l}\text { Experiences of quarantine: yes } \\
\text { (vs. no) }\end{array}$ & $1.35(1.25-1.46)$ & $<0.001$ & $1.34(1.24-1.44)$ & $<0.001$ & $1.29(1.20-1.40)$ & $<0.001$ & $1.31(1.22-1.41)$ & $<0.001$ \\
\hline $\begin{array}{l}\text { Living in province most severely } \\
\text { affected by initial peak: yes (vs. no) }\end{array}$ & $1.28(1.10-1.49)$ & 0.002 & $1.32(1.14-1.53)$ & $<0.001$ & $1.19(1.02-1.39)$ & 0.03 & $1.21(1.04-1.41)$ & 0.01 \\
\hline $\begin{array}{l}\text { Self-perceived occupational exposure } \\
\text { risk to COVID-19: yes (vs. no) }\end{array}$ & $1.33(1.20-1.48)$ & $<0.001$ & $1.39(1.26-1.54)$ & $<0.001$ & $1.18(1.06-1.31)$ & 0.002 & $1.26(1.14-1.40)$ & $<0.001$ \\
\hline $\begin{array}{l}\text { Living in places with COVID-19 } \\
\text { resurgences: yes (vs. no) }\end{array}$ & $1.36(1.24-1.49)$ & $<0.001$ & $1.30(1.18-1.42)$ & $<0.001$ & $1.37(1.25-1.50)$ & $<0.001$ & $1.38(1.26-1.50)$ & $<0.001$ \\
\hline $\begin{array}{l}\text { Wearing face masks voluntarily } \\
\text { when going out: yes (vs. no) }\end{array}$ & $0.70(0.58-0.85)$ & $<0.001$ & $0.71(0.59-0.87)$ & $<0.001$ & $0.75(0.62-0.90)$ & 0.003 & $0.74(0.61-0.90)$ & 0.003 \\
\hline $\begin{array}{l}\text { Reducing social gatherings } \\
\text { voluntarily: yes (vs. no) }\end{array}$ & $0.84(0.74-0.95)$ & 0.004 & $0.92(0.82-1.03)$ & 0.16 & $0.83(0.74-0.94)$ & 0.003 & $0.93(0.83-1.04)$ & 0.22 \\
\hline $\begin{array}{l}\text { Seeking psychological consultation } \\
\text { since COVID-19: yes (vs. no) }\end{array}$ & $2.81(2.55-3.10)$ & $<0.001$ & $2.78(2.52-3.06)$ & $<0.001$ & $2.36(2.14-2.60)$ & $<0.001$ & $2.57(2.33-2.85)$ & $<0.001$ \\
\hline
\end{tabular}

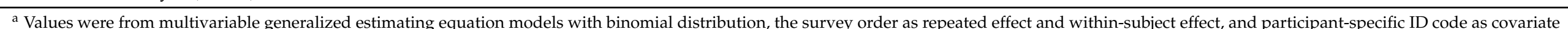

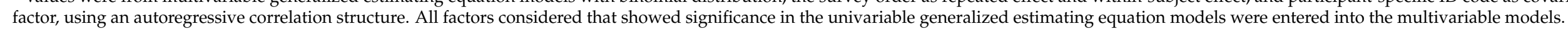




\subsection{Factors Associated with Scores of Depression, Anxiety and Insomnia Symptoms during the Course of COVID-19}

Table 5 presents the multivariable generalized linear mixed-effects analysis with outcome variables being continuous PHQ-9, GAD-7 and ISI scores, and the fixed effects for all factors detected significant in the multivariable generalized estimating equation analysis remained statistically significant. Furthermore, we found that the highly educated, those living in places with COVID-19 resurgences, those reporting increases in work burden after resuming work and those seeking psychological consultation since COVID-19 experienced a steeper increase in depressive, anxiety or insomnia symptoms, while those who wore facemasks or reduced social gatherings voluntarily experienced a milder increase in the three symptoms over the course of COVID-19 (Figures S1-S6), as indicated by significant factor by time interactions in the multivariable generalized linear mixed-effects models.

Table 5. Associated factors of scores of depression, anxiety and insomnia symptoms during the course of COVID-19 in the multivariable generalized linear mixed models ${ }^{a}$.

\begin{tabular}{|c|c|c|c|c|c|c|}
\hline \multirow{2}{*}{ Factors } & \multicolumn{2}{|c|}{ Depression } & \multicolumn{2}{|c|}{ Anxiety } & \multicolumn{2}{|c|}{ Insomnia } \\
\hline & b (SE) & $p$-Value & b (SE) & $p$-Value & b (SE) & $p$-Value \\
\hline Gender: male (vs. female) & $0.37(0.08)$ & $<0.001$ & $0.06(0.07)$ & 0.39 & $0.34(0.09)$ & $<0.001$ \\
\hline Age (years) & $-0.02(0.01)$ & $<0.001$ & $-0.01(0.00)$ & 0.007 & $0.01(0.01)$ & 0.15 \\
\hline Marital status: married (vs unmarried) & $-0.38(0.11)$ & $<0.001$ & $-0.02(0.09)$ & 0.82 & $-0.70(0.12)$ & $<0.001$ \\
\hline $\begin{array}{l}\text { Family members of COVID-19 patients: } \\
\text { yes (vs. no) }\end{array}$ & $1.48(0.30)$ & $<0.001$ & $1.44(0.25)$ & $<0.001$ & $1.99(0.31)$ & $<0.001$ \\
\hline Experiences of quarantine: yes (vs. no) & $0.74(0.08)$ & $<0.001$ & $0.64(0.07)$ & $<0.001$ & $0.58(0.09)$ & $<0.001$ \\
\hline $\begin{array}{l}\text { Living in province most severely affected } \\
\text { by initial peak: yes (vs. no) }\end{array}$ & $0.81(0.18)$ & $<0.001$ & $1.04(0.16)$ & $<0.001$ & $0.71(0.20)$ & $<0.001$ \\
\hline $\begin{array}{l}\text { Self-perceived occupational exposure risk } \\
\text { to COVID-19: yes (vs. no) }\end{array}$ & $0.87(0.12)$ & $<0.001$ & $0.70(0.10)$ & $<0.001$ & $0.38(0.13)$ & 0.003 \\
\hline $\begin{array}{l}\text { Living in places with COVID-19 } \\
\text { resurgences: yes (vs. no) }\end{array}$ & $0.69(0.10)$ & $<0.001$ & $0.45(0.09)$ & $<0.001$ & $0.83(0.11)$ & $<0.001$ \\
\hline $\begin{array}{c}\text { Increases in work burden after resuming } \\
\text { work: yes (vs. no) }\end{array}$ & 1.07 (0.08) & $<0.001$ & $1.02(0.07)$ & $<0.001$ & $1.27(0.09)$ & $<0.001$ \\
\hline $\begin{array}{l}\text { Wearing face masks voluntarily when } \\
\text { going out: yes (vs. no) }\end{array}$ & $-0.93(0.23)$ & $<0.001$ & $-0.56(0.20)$ & 0.004 & $-0.72(0.24)$ & 0.003 \\
\hline $\begin{array}{c}\text { Reducing social gatherings voluntarily: } \\
\text { yes (vs. no) }\end{array}$ & $-0.51(0.14)$ & $<0.001$ & $-0.15(0.12)$ & 0.21 & $-0.22(0.15)$ & 0.14 \\
\hline $\begin{array}{l}\text { Seeking psychological consultation since } \\
\text { COVID-19: yes (vs. no) }\end{array}$ & $2.72(0.12)$ & $<0.001$ & $2.03(0.11)$ & $<0.001$ & $1.82(0.13)$ & $<0.001$ \\
\hline $\begin{array}{l}\text { Educational level } \times \text { time: college school or } \\
\text { higher (vs. lower than college school) }\end{array}$ & $0.02(0.01)$ & 0.03 & $0.03(0.01)$ & 0.003 & $0.05(0.01)$ & 0.001 \\
\hline $\begin{array}{l}\text { Living in places with COVID-19 } \\
\text { resurgences } \times \text { time: yes (vs. no) }\end{array}$ & $0.03(0.01)$ & 0.003 & $0.04(0.01)$ & 0.002 & $0.03(0.02)$ & 0.10 \\
\hline $\begin{array}{l}\text { Increases in work burden after resuming } \\
\text { work } \times \text { time: yes (vs. no) }\end{array}$ & $0.04(0.01)$ & $<0.001$ & $0.02(0.01)$ & 0.04 & $0.09(0.01)$ & $<0.001$ \\
\hline $\begin{array}{l}\text { Wearing face masks voluntarily when } \\
\text { going out } \times \text { time: yes (vs. no) }\end{array}$ & $-0.07(0.03)$ & 0.005 & $-0.07(0.03)$ & 0.02 & $-0.05(0.04)$ & 0.17 \\
\hline $\begin{array}{c}\text { Reducing social gatherings voluntarily } \times \\
\text { time: yes (vs. no) }\end{array}$ & $-0.02(0.01)$ & 0.15 & $-0.05(0.02)$ & 0.003 & $-0.08(0.02)$ & $<0.001$ \\
\hline $\begin{array}{l}\text { Seeking psychological consultation since } \\
\text { COVID-19 } \times \text { time: yes (vs. no) }\end{array}$ & $0.21(0.02)$ & $<0.001$ & $0.19(0.02)$ & $<0.001$ & $0.21(0.02)$ & $<0.001$ \\
\hline
\end{tabular}

${ }^{a}$ Values were from multivariable generalized linear mixed models with random within-subject intercepts and autoregressive covariance structures. The multivariable models included fixed effects for time (coded as 0 at baseline, and 5 at follow-up), as well as all factors and their interaction terms with time that showed significance in their individual univariable generalized linear mixed models. 


\section{Discussion}

This large-sample national cohort in China investigated the longitudinal changes in mental health symptoms from the initial peak of COVID-19 to its aftermath five months later. In both baseline and follow-up surveys, over $40 \%$ participants reported mental health symptoms, suggesting a consistently severe mental health burden during the COVID-19 pandemic. Our study further found about a quarter new onset and seven over ten persistent mental health symptoms among those without or with mental health symptoms at baseline. We identified personal (quarantine and living in places severely affected by initial peak or hit by COVID-19 resurgences) and work factors (occupational exposure risk to COVID-19 and increases in work burden after resuming work) to be associated with long-term mental health symptoms. In addition, special attention should be paid to family members of COVID-19 patients and those seeking psychological consultation. Some self-protection measures (wearing face masks and reducing social gatherings) were identified as potential protective factors for mental health symptoms. Given the continuous emergence of new cases and normalization of pandemic control, these findings can be valuable for long-term mental health management in the worldwide and persistent battle with COVID-19.

In other countries, longitudinal studies reported inconsistent temporal trends in mental health symptoms during COVID-19, but we found consistently elevated mental health symptoms in China. The UK reported a pronounced increase in distress immediately after the COVID-19 outbreak, followed by a rapid recovery [23,33]. Italy demonstrated a worsening trend in mental health during lockdown, while during the initial peak in the United States, psychological distress remained largely stable [24,25]. All these studies just focused on the changes in mental health status within the initial peak and lockdown period, while our study tracked the mental health changes from the initial peak to its aftermath, when the initial outbreak had been put under control, and lockdown had been lifted for about three months. Specifically, in this cohort study, $69.0 \%$ of participants with distress at baseline still reported distress at follow-up, while new cases of mental health symptoms emerged in $24.4 \%$ of the baseline symptom-free participants. The prolonged deterioration in mental health, despite an improvement in pandemic control, might be due to prominent social repercussions including pervasive public health measures and economical stress, as well as the frequent COVID-19 resurgences [26-28].

Within all demographic subgroups, the prevalence of mental health symptoms remained largely unchanged over time, although this symptom persistence was more evident among males and young people, as well as highly educated, impoverished and unmarried populations. Young adults' long-term distress may be attributable to their higher exposure to social media and misinformation, more significant increases in work burden as well as more insecurity in jobs and finance $[34,35]$. Well-educated people harbor more interest in health-related information, thus are more likely to be psychologically influenced by COVID-19 [36]. Impoverished people may be less capable of coping with the financial adversities caused by the economic downturn following COVID-19, which can breed long-term distress [33].

Several personal and work-related factors were associated with long-term mental health symptoms. Personal factors mainly included quarantine and living in places severely affected by initial peak or hit by COVID-19 resurgences. Quarantine has become a regular international intervention for COVID-19 [37], but quarantine induces lonely feelings and financial damage, with long-term mental health consequences [38,39]. Shorter quarantine duration, simplification of quarantine procedures and more knowledge about the benefits of quarantine can lower long-term psychological risk [40]. Apart from quarantine, this study combined with our previous finding [9] suggests that people living in the place most severely affected by initial peak of COVID-19 are at risk of long-term mental health problems even after the end of lockdown and removal of strong intervention measures during the initial peak [41]. In addition, COVID-19 resurgence is closely related to long-term mental health outcomes and a steeper longitudinal increase in symptom severity. Victims repeatedly exposed to similar disasters, such as earthquakes and tsunamis, as a result of 
these "repeated blows" are more susceptible to long-term distress [42,43]. Additionally, places hit by COVID-19 resurgences tend to be located adjacent to borders, which place them under persistent threat of imported cases and insecurity even when the domestic epidemic has been controlled [44,45]. Future studies are called for to further ascertain the mental health changing trend among people living in places severely affected by initial peak of COVID-19 or hit by COVID-19 resurgence over the long course of COVID-19.

Regarding work-related factors, self-perceived occupational exposure risk to COVID19 and increases in work burden after resuming work were related with long-term mental health problems. People with high occupational exposure risk to COVID-19 were also psychologically vulnerable populations due to long-lasting fear, traumatic events and heavier workloads $[9,46]$, which is consistent with previous studies of essential workers during epidemics $[19,47,48]$. In addition, approximately $40 \%$ of participants reported an increase in work burden after resuming work. High work load could lead to burnout, and enhance the risk of adverse mental health outcomes [49-51]. This points out that appropriate work allocation is necessary for prompting mental health during the COVID19 pandemic and its recovery period.

We also found that participants obtaining psychological consultation were about three times more susceptible to long-term mental health symptoms, and over $70 \%$ of them reported distress at follow-up in the present study. After SARS a similar increase in seeking psychological consultation occurred [52], suggesting it was a potential warning signal for long-term distress following pandemics, and our study further indicated its potential in predicting a more pronounced temporal mental health deterioration over the course of COVID-19. Thus, those seeking psychological consultation deserve special attention for their mental health status during and after the initial peak of COVID-19 pandemic. Moreover, consistent with previous studies [53], family members of COVID-19 patients needed to be looked out for mental health symptoms. Specially, more understanding and support should be provided for families with deceased COVID-19 patients [54,55].

Protective factors that emerged were voluntarily wearing face masks when going out and reducing social gatherings. This may be due to the sense of security and altruism brought by self-protection measures during epidemics [56,57]. As positive attitudes towards and belief in effectiveness of self-protection measures can increase public compliance, the government is suggested to impart benefits of wearing face masks and keeping social distance to the public, which may bring about long-term merits [58,59]. However, the causal relationship between usage of self-protection measures and mental health should be interpreted with caution for those having fewer mental health problems may tend to comply with guidance on personal protective practices.

\section{Strengths and Limitations}

This study is among the earliest investigations tracking changes in mental health from the initial peak of COVID-19 to its aftermath. We come to our conclusions based on a nationwide and large cohort. The longitudinal within-subject design and repeated measurement on the same platform enabled us to explore the temporal changes with less chance of sampling and survey method bias. Additionally, we managed to longitudinally measure mental health symptoms across distinctive stages of COVID-19, and identified vulnerable populations that emerged during the initial peak and in its aftermath. Therefore, we believe our results can serve as a model for evolving mental health trends and offer some guidance for population- and phase-specific mental health management under the global enduring COVID-19 threat.

Our study has several limitations. These limitations include the observation time of only about five months, which might not be long enough to capture the complete psychological evolving trend during COVID-19. Moreover, evolving patterns and control levels of COVID-19 vary across countries, so application of our results to other countries should be made with caution. Future studies with longer follow-up time and from different countries are needed. Other limitations include the possible selection bias, low follow- 
up rate and failure to report reasons of drop-out. Although this study had extensive geographic coverage across China and a large sample size, selection bias still existed as all participants were paid members of a commercial website and were characteristically young and highly educated despite the fact that follow-up responders over-represented females, the elderly and the poorly educated, which warranted cautions when generalizing our results to larger populations. Finally, mental health symptoms were based on self-reported questionnaires instead of clinical diagnoses, so future studies employing more precise diagnostic methods are needed.

\section{Conclusions}

Our nationwide large-sample cohort study in China found susceptible populations during the initial COVID-19 peak suffered from enduring long-term mental health outcomes that still persisted in the aftermath of the initial peak. These populations included family members of COVID-19 patients, people with quarantine experiences, residents living in severely affected regions at the initial peak and people with occupational exposure risk to COVID-19. We further identified some new vulnerable populations that emerged after the initial peak, such as those living in places hit by COVID-19 resurgence, those seeking psychological consultation since COVID-19 and those experiencing increases in work burden after resuming work. Nonetheless, the significance of these results in the real world should be further validated in future researches. Our investigation reveals a severe and enduring mental health burden during the COVID-19 pandemic, suggesting essential long-term and regular mental health management throughout the whole course of COVID-19. This management will include making population- and phase-specific mental health intervention strategies during COVID-19.

Supplementary Materials: The following are available online at https:/ / www.mdpi.com/article/10 .3390 /ijerph18168790/s1, Figure S1: Changes in scores of depression, anxiety and insomnia from baseline to follow-up stratified by COVID-19 resurgence; Figure S2: Changes in scores of depression, anxiety and insomnia from baseline to follow-up stratified by increases in work burden after resuming work; Figure S3: Changes in scores of depression, anxiety and insomnia from baseline to follow-up stratified by educational level; Figure S4: Changes in scores of depression, anxiety and insomnia from baseline to follow-up stratified by voluntarily wearing face masks; Figure S5: Changes in scores of depression, anxiety and insomnia from baseline to follow-up stratified by voluntarily reducing social gatherings, Figure S6: Changes in scores of depression, anxiety and insomnia from baseline to follow-up stratified by seeking psychological consultation. Table S1: STROBE checklist for cohort studies; Table S2: Summary of questions of the questionnaire related to this study; Table S3: Factors associated with long-term mental health symptoms in the multivariable regression model; Table S4: Changes in prevalence of mental health symptoms from baseline to follow-up stratified by demographic and epidemic-related factors.

Author Contributions: L.S. and Z.-A.L. contributed equally to this article; L.S., Z.-A.L., Y.-P.B. and L.L. (Lin Lu) proposed the topic and main idea; Z.-A.L. analyzed the data; Z.-A.L. and L.S. wrote the initial draft of the manuscript; J.-Y.Q., X.-L.H., Q.-D.L., L.L. (Lin Liu), Y.-B.Z., W.-J.L., M.-S.R., K.Y., W.Y., Y.-K.S., S.-W.S., J.S., T.K., Y.-P.B. and L.L. (Lin Lu) commented on and revised the manuscript; L.L. (Lin Lu) finalized the manuscript, with contributions from all authors. All authors have read and agreed to the published version of the manuscript.

Funding: This study was supported by grants from the National Natural Science Foundation of China (grant numbers 81761128036, 81821092 and 31900805), and the National Key Research and Development Program of China (no. 2021YFC0863700 and 2019YFA0706200).

Institutional Review Board Statement: The study was approved by the ethics committee of Peking University Sixth Hospital (Institute of Mental Health), and followed the American Association for Public Opinion Research (AAPOR) reporting guideline.

Informed Consent Statement: Informed consent was obtained from all subjects involved in the study.

Data Availability Statement: The corresponding authors have full access to all the data in the study and take responsibility for the integrity of the data and the accuracy of the data analysis. 
Conflicts of Interest: The authors declare no conflict of interest.

\section{References}

1. World Health Organization. Coronavirus Disease (COVID-19) Pandemic. 2021. Available online: https://www.who.int/ emergencies/diseases/novel-coronavirus-2019 (accessed on 7 August 2021).

2. Meo, S.A.; Alhowikan, A.M.; Al-Khlaiwi, T.; Meo, I.M.; Halepoto, D.M.; Iqbal, M.; Usmani, A.M.; Hajjar, W.; Ahmed, N. Novel coronavirus 2019-nCoV: Prevalence, biological and clinical characteristics comparison with SARS-CoV and MERS-CoV. Eur. Rev. Med. Pharmacol. Sci. 2020, 24, 2012-2019. [CrossRef] [PubMed]

3. Jeyanathan, M.; Afkhami, S.; Smaill, F.; Miller, M.S.; Lichty, B.D.; Xing, Z. Immunological considerations for COVID-19 vaccine strategies. Nat. Rev. Immunol. 2020, 20, 615-632. [CrossRef] [PubMed]

4. $\quad$ Pierce, M.; Hope, H.; Ford, T.; Hatch, S.; Hotopf, M.; John, A.; Kontopantelis, E.; Webb, R.; Wessely, S.; McManus, S.; et al. Mental health before and during the COVID-19 pandemic: A longitudinal probability sample survey of the UK population. Lancet Psychiatry 2020, 7, 883-892. [CrossRef]

5. Bao, Y.; Sun, Y.; Meng, S.; Shi, J.; Lu, L. 2019-nCoV epidemic: Address mental health care to empower society. Lancet 2020, 395, e37-e38. [CrossRef]

6. Liu, J.J.; Bao, Y.; Huang, X.; Shi, J.; Lu, L. Mental health considerations for children quarantined because of COVID-19. Lancet Child Adolesc. Health 2020, 4, 347-349. [CrossRef]

7. Salari, N.; Hosseinian-Far, A.; Jalali, R.; Vaisi-Raygani, A.; Rasoulpoor, S.; Mohammadi, M.; Rasoulpoor, S.; Khaledi-Paveh, B Prevalence of stress, anxiety, depression among the general population during the COVID-19 pandemic: A systematic review and meta-analysis. Glob. Health 2020, 16, 57. [CrossRef] [PubMed]

8. Luo, M.; Guo, L.; Yu, M.; Jiang, W.; Wang, H. The psychological and mental impact of coronavirus disease 2019 (COVID-19) on medical staff and general public-A systematic review and meta-analysis. Psychiatry Res. 2020, 291, 113190. [CrossRef] [PubMed]

9. Shi, L.; Lu, Z.A.; Que, J.Y.; Huang, X.L.; Liu, L.; Ran, M.S.; Gong, Y.M.; Yuan, K.; Yan, W.; Sun, Y.K.; et al. Prevalence of and Risk Factors Associated With Mental Health Symptoms Among the General Population in China During the Coronavirus Disease 2019 Pandemic. JAMA Netw. Open 2020, 3, e2014053. [CrossRef]

10. Gupta, S.; Goren, A.; Dong, P.; Liu, D. Prevalence, awareness, and burden of major depressive disorder in urban China. Expert Rev. Pharm. Outcomes Res. 2016, 16, 393-407. [CrossRef]

11. Zhou, X.; Bi, B.; Zheng, L.; Li, Z.; Yang, H.; Song, H.; Sun, Y. The prevalence and risk factors for depression symptoms in a rural Chinese sample population. PLoS ONE 2014, 9, e99692. [CrossRef]

12. Yu, W.; Singh, S.S.; Calhoun, S.; Zhang, H.; Zhao, X.; Yang, F. Generalized anxiety disorder in urban China: Prevalence, awareness, and disease burden. J. Affect. Disord. 2018, 234, 89-96. [CrossRef]

13. Cao, X.L.; Wang, S.B.; Zhong, B.L.; Zhang, L.; Ungvari, G.S.; Ng, C.H.; Li, L.; Chiu, H.F.; Lok, G.K.; Lu, J.P.; et al. The prevalence of insomnia in the general population in China: A meta-analysis. PLoS ONE 2017, 12, e0170772. [CrossRef] [PubMed]

14. Guo, Y.; Cheng, C.; Zeng, Y.; Li, Y.; Zhu, M.; Yang, W.; Xu, H.; Li, X.; Leng, J.; Monroe-Wise, A.; et al. Mental Health Disorders and Associated Risk Factors in Quarantined Adults During the COVID-19 Outbreak in China: Cross-Sectional Study. J. Med. Internet Res. 2020, 22, e20328. [CrossRef]

15. Venkatesh, A.; Edirappuli, S. Social distancing in COVID-19: What are the mental health implications? BMJ 2020, 369, m1379. [CrossRef] [PubMed]

16. Gualano, M.R.; Lo Moro, G.; Voglino, G.; Bert, F.; Siliquini, R. Effects of Covid-19 Lockdown on Mental Health and Sleep Disturbances in Italy. Int. J. Environ. Res. Public Health 2020, 17, 4779. [CrossRef]

17. Wang, Y.; Shi, L.; Que, J.; Lu, Q.; Liu, L.; Lu, Z.; Xu, Y.; Liu, J.; Sun, Y.; Meng, S.; et al. The impact of quarantine on mental health status among general population in China during the COVID-19 pandemic. Mol. Psychiatry 2021, 1-10. [CrossRef]

18. Lee, A.M.; Wong, J.G.; McAlonan, G.M.; Cheung, V.; Cheung, C.; Sham, P.C.; Chu, C.M.; Wong, P.C.; Tsang, K.W.; Chua, S.E. Stress and psychological distress among SARS survivors 1 year after the outbreak. Can. J. Psychiatry 2007, 52, 233-240. [CrossRef]

19. Maunder, R.G.; Lancee, W.J.; Balderson, K.E.; Bennett, J.P.; Borgundvaag, B.; Evans, S.; Fernandes, C.M.; Goldbloom, D.S.; Gupta, M.; Hunter, J.J.; et al. Long-term psychological and occupational effects of providing hospital healthcare during SARS outbreak. Emerg. Infect. Dis. 2006, 12, 1924-1932. [CrossRef] [PubMed]

20. Kwek, S.K.; Chew, W.M.; Ong, K.C.; Ng, A.W.; Lee, L.S.; Kaw, G.; Leow, M.K. Quality of life and psychological status in survivors of severe acute respiratory syndrome at 3 months postdischarge. J. Psychosom. Res. 2006, 60, 513-519. [CrossRef] [PubMed]

21. Liu, X.; Kakade, M.; Fuller, C.J.; Fan, B.; Fang, Y.; Kong, J.; Guan, Z.; Wu, P. Depression after exposure to stressful events: Lessons learned from the severe acute respiratory syndrome epidemic. Compr. Psychiatry 2012, 53, 15-23. [CrossRef]

22. Daly, M.; Robinson, E. Psychological distress and adaptation to the COVID-19 crisis in the United States. J. Psychiatr. Res. 2021, 136, 603-609. [CrossRef]

23. Daly, M.; Sutin, A.; Robinson, E. Longitudinal changes in mental health and the COVID-19 pandemic: Evidence from the UK Household Longitudinal Study. Psychol. Med. 2020, 1-10. [CrossRef] [PubMed]

24. Fiorillo, A.; Sampogna, G.; Giallonardo, V.; Del Vecchio, V.; Luciano, M.; Albert, U.; Carmassi, C.; Carrà, G.; Cirulli, F.; Dell'Osso, B.; et al. Effects of the lockdown on the mental health of the general population during the COVID-19 pandemic in Italy: Results from the COMET collaborative network. Eur. Psychiatry 2020, 63, e87. [CrossRef] [PubMed] 
25. McGinty, E.E.; Presskreischer, R.; Anderson, K.E.; Han, H.; Barry, C.L. Psychological Distress and COVID-19-Related Stressors Reported in a Longitudinal Cohort of US Adults in April and July 2020. JAMA 2020, 324, 2555-2557. [CrossRef] [PubMed]

26. Xu, T.L.; Ao, M.Y.; Zhou, X.; Zhu, W.F.; Nie, H.Y.; Fang, J.H.; Sun, X.; Zheng, B.; Chen, X.F. China's practice to prevent and control COVID-19 in the context of large population movement. Infect. Dis. Poverty 2020, 9, 115. [CrossRef]

27. Shen, J.; Duan, H.; Zhang, B.; Wang, J.; Ji, J.S.; Wang, J.; Pan, L.; Wang, X.; Zhao, K.; Ying, B.; et al. Prevention and control of COVID-19 in public transportation: Experience from China. Environ. Pollut. 2020, 266 (Pt 2), 115291. [CrossRef]

28. Zhang, J.; Wu, S.; Xu, L. Asymptomatic carriers of COVID-19 as a concern for disease prevention and control: More testing, more follow-up. Biosci. Trends 2020, 14, 206-208. [CrossRef]

29. Holmes, E.A.; O'Connor, R.C.; Perry, V.H.; Tracey, I.; Wessely, S.; Arseneault, L.; Ballard, C.; Christensen, H.; Cohen Silver, R.; Everall, I.; et al. Multidisciplinary research priorities for the COVID-19 pandemic: A call for action for mental health science. Lancet Psychiatry 2020, 7, 547-560. [CrossRef]

30. Kroenke, K.; Spitzer, R.L.; Williams, J.B. The PHQ-9: Validity of a brief depression severity measure. J. Gen. Intern. Med. 2001, 16, 606-613. [CrossRef] [PubMed]

31. Löwe, B.; Decker, O.; Müller, S.; Brähler, E.; Schellberg, D.; Herzog, W.; Herzberg, P.Y. Validation and standardization of the Generalized Anxiety Disorder Screener (GAD-7) in the general population. Med. Care 2008, 46, 266-274. [CrossRef] [PubMed]

32. Gagnon, C.; Bélanger, L.; Ivers, H.; Morin, C.M. Validation of the Insomnia Severity Index in primary care. J. Am. Board Fam. Med. 2013, 26, 701-710. [CrossRef] [PubMed]

33. Fancourt, D.; Steptoe, A.; Bu, F. Trajectories of anxiety and depressive symptoms during enforced isolation due to COVID-19 in England: A longitudinal observational study. Lancet Psychiatry 2021, 8, 141-149. [CrossRef]

34. The, L. Social media, screen time, and young people's mental health. Lancet 2019, 393, 611. [CrossRef]

35. Ganson, K.T.; Tsai, A.C.; Weiser, S.D.; Benabou, S.E.; Nagata, J.M. Job Insecurity and Symptoms of Anxiety and Depression Among U.S. Young Adults During COVID-19. J. Adolesc. Health 2021, 68, 53-56. [CrossRef] [PubMed]

36. Saha, S. Improving literacy as a means to reducing health disparities. J. Gen. Intern. Med. 2006, 21, 893-895. [CrossRef]

37. Tang, B.; Xia, F.; Tang, S.; Bragazzi, N.L.; Li, Q.; Sun, X.; Liang, J.; Xiao, Y.; Wu, J. The effectiveness of quarantine and isolation determine the trend of the COVID-19 epidemics in the final phase of the current outbreak in China. Int. J. Infect. Dis. 2020, 95, 288-293. [CrossRef] [PubMed]

38. Brooks, S.K.; Webster, R.K.; Smith, L.E.; Woodland, L.; Wessely, S.; Greenberg, N.; Rubin, G.J. The psychological impact of quarantine and how to reduce it: Rapid review of the evidence. Lancet 2020, 395, 912-920. [CrossRef]

39. Hawryluck, L.; Gold, W.L.; Robinson, S.; Pogorski, S.; Galea, S.; Styra, R. SARS control and psychological effects of quarantine, Toronto, Canada. Emerg. Infect. Dis. 2004, 10, 1206-1212. [CrossRef] [PubMed]

40. Reynolds, D.L.; Garay, J.R.; Deamond, S.L.; Moran, M.K.; Gold, W.; Styra, R. Understanding, compliance and psychological impact of the SARS quarantine experience. Epidemiol. Infect. 2008, 136, 997-1007. [CrossRef] [PubMed]

41. Cao, S.; Gan, Y.; Wang, C.; Bachmann, M.; Wei, S.; Gong, J.; Huang, Y.; Wang, T.; Li, L.; Lu, K.; et al. Post-lockdown SARS-CoV-2 nucleic acid screening in nearly ten million residents of Wuhan, China. Nat. Commun. 2020, 11, 5917. [CrossRef] [PubMed]

42. Spittlehouse, J.K.; Joyce, P.R.; Vierck, E.; Schluter, P.J.; Pearson, J.F. Ongoing adverse mental health impact of the earthquake sequence in Christchurch, New Zealand. Aust. N. Z. J. Psychiatry 2014, 48, 756-763. [CrossRef]

43. Tang, W.; Zhao, J.; Lu, Y.; Yan, T.; Wang, L.; Zhang, J.; Xu, J. Mental health problems among children and adolescents experiencing two major earthquakes in remote mountainous regions: A longitudinal study. Compr. Psychiatry 2017, 72, 66-73. [CrossRef] [PubMed]

44. Ren, Y.; Qian, W.; Li, Z.; Liu, Z.; Zhou, Y.; Wang, R.; Qi, L.; Yang, J.; Song, X.; Zeng, L.; et al. Public mental health under the long-term influence of COVID-19 in China: Geographical and temporal distribution. J. Affect. Disord. 2020, 277, 893-900. [CrossRef]

45. Kim, A.W.; Nyengerai, T.; Mendenhall, E. Evaluating the mental health impacts of the COVID-19 pandemic: Perceived risk of COVID-19 infection and childhood trauma predict adult depressive symptoms in urban South Africa. Psychol. Med. 2020, 34, 1475-1482. [CrossRef] [PubMed]

46. Iob, E.; Frank, P.; Steptoe, A.; Fancourt, D. Levels of Severity of Depressive Symptoms Among At-Risk Groups in the UK During the COVID-19 Pandemic. JAMA Netw. Open 2020, 3, e2026064. [CrossRef]

47. Wu, P.; Fang, Y.; Guan, Z.; Fan, B.; Kong, J.; Yao, Z.; Liu, X.; Fuller, C.J.; Susser, E.; Lu, J.; et al. The psychological impact of the SARS epidemic on hospital employees in China: Exposure, risk perception, and altruistic acceptance of risk. Can. J. Psychiatry 2009, 54, 302-311. [CrossRef] [PubMed]

48. Que, J.; Shi, L.; Deng, J.; Liu, J.; Zhang, L.; Wu, S.; Gong, Y.; Huang, W.; Yuan, K.; Yan, W.; et al. Psychological impact of the COVID-19 pandemic on healthcare workers: A cross-sectional study in China. Gen. Psychiatr. 2020, 33, e100259. [CrossRef] [PubMed]

49. Maslach, C.; Leiter, M.P. Understanding the burnout experience: Recent research and its implications for psychiatry. World Psychiatry 2016, 15, 103-111. [CrossRef]

50. Shaw, W.S.; Main, C.J.; Findley, P.A.; Collie, A.; Kristman, V.L.; Gross, D.P. Opening the Workplace After COVID-19: What Lessons Can be Learned from Return-to-Work Research? J. Occup. Rehabil. 2020, 30, 299-302. [CrossRef] 
51. Harvey, S.B.; Modini, M.; Joyce, S.; Milligan-Saville, J.S.; Tan, L.; Mykletun, A.; Bryant, R.A.; Christensen, H.; Mitchell, P.B. Can work make you mentally ill? A systematic meta-review of work-related risk factors for common mental health problems. Occup. Environ. Med. 2017, 74, 301-310. [CrossRef]

52. Wu, K.K.; Chan, S.K.; Ma, T.M. Posttraumatic stress after SARS. Emerg. Infect. Dis. 2005, 11, 1297-1300. [CrossRef]

53. Tanoue, Y.; Nomura, S.; Yoneoka, D.; Kawashima, T.; Eguchi, A.; Shi, S.; Harada, N.; Miyata, H. Mental health of family, friends, and co-workers of COVID-19 patients in Japan. Psychiatry Res. 2020, 291, 113067. [CrossRef]

54. Singer, J.; Spiegel, J.A.; Papa, A. Preloss grief in family members of COVID-19 patients: Recommendations for clinicians and researchers. Psychol. Trauma 2020, 12, S90-S93. [CrossRef]

55. Endomba, F.T.; Wafeu, G.S.; Efon-Ekangouo, A.; Djune-Yemeli, L.; Donfo-Azafack, C.; Nana-Djeunga, H.C.; Kamgno, J. Support for families of isolated or deceased COVID-19 patients in sub-Saharan Africa. Health Psychol. Open 2020, 7, 2055102920975293. [CrossRef]

56. Lam, S.C.; Arora, T.; Grey, I.; Suen, L.K.P.; Huang, E.Y.; Li, D.; Lam, K.B.H. Perceived Risk and Protection From Infection and Depressive Symptoms Among Healthcare Workers in Mainland China and Hong Kong During COVID-19. Front. Psychiatry 2020, 11, 686. [CrossRef] [PubMed]

57. Scheid, J.L.; Lupien, S.P.; Ford, G.S.; West, S.L. Commentary: Physiological and Psychological Impact of Face Mask Usage during the COVID-19 Pandemic. Int. J. Environ. Res. Public Health 2020, 17, 6655. [CrossRef] [PubMed]

58. Fisher, K.A.; Barile, J.P.; Guerin, R.J.; Vanden Esschert, K.L.; Jeffers, A.; Tian, L.H.; Garcia-Williams, A.; Gurbaxani, B.; Thompson, W.W.; Prue, C.E. Factors Associated with Cloth Face Covering Use Among Adults During the COVID-19 Pandemic-United States, April and May 2020. MMWR Morb. Mortal. Wkly. Rep. 2020, 69, 933-937. [CrossRef] [PubMed]

59. Zhao, S.Z.; Wong, J.Y.H.; Wu, Y.; Choi, E.P.H.; Wang, M.P.; Lam, T.H. Social Distancing Compliance under COVID-19 Pandemic and Mental Health Impacts: A Population-Based Study. Int. J. Environ. Res. Public Health 2020, 17, 6692. [CrossRef] [PubMed] 